\title{
Lipid peroxidation and antioxidant status in blood of patients with uterine myoma, endometrial polypus, hyperplastic and malignant endometrium
}

\author{
SNEŽANA PEJIĆ, JELENA KASAPOVIĆ, ANA TODOROVIĆ, \\ VESNA STOJILJKOVIĆ, and SNEŽANA B. PAJOVIĆ
}

Laboratory of Molecular Biology and Endocrinology, Vinča Institute of Nuclear Sciences, Belgrade, Serbia

\begin{abstract}
Oxidative stress is considered to be involved in pathogenesis of many disorders of the female genital tract. In this study, we explored the lipid peroxidation levels and antioxidant enzyme activities in women diagnosed with different forms of uterine diseases in order to evaluate the extent of oxidative stress in blood of such patients. Blood samples of healthy subjects and gynecological patients were collected and subjected to assays for superoxide dismutase, catalase, glutathione peroxidase, glutathione reductase and lipid hydroperoxides. The results show that alterations of measured parameters vary with the enzyme type and diagnosis. However, both reduction in antioxidants and elevation of lipid peroxidation were observed in general. Lipid hydroperoxides level was negatively correlated to superoxide dismutase and glutathione peroxidase activities, as well as positively correlated to catalase activity. In addition, the lipid hydroperoxides/glutathione peroxidase ratio was found to be increased, according to the type of uterine disease. The obtained results show that perturbation of antioxidant status is more pronounced in blood of patients with premalignant (hyperplastic) and malignant (adenocarcinoma) lesions, compared to those with benign uterine changes such as polypus and myoma.
\end{abstract}

Key terms: antioxidant enzymes, endometrial polypus, endometrial hyperplasia, endometrial adenocarcinoma, lipid peroxidation, uterine myoma,

\section{INTRODUCTION}

It is widely accepted that excess production of free radicals, particularly oxygen radicals, creates a condition known as oxidative stress, which causes cell damage and plays fundamental role in various diseases, aging and neoplastic transformation (Sun, 1990; Halliwell, 1996). Also, by-products of lipid peroxidation perturb structural organization and functions of the cell membrane, consequently leading to cell destruction (Porter et al., 1995; Spiteller, 2003). Deleterious effects of reactive oxygen species (ROS) and lipid peroxidation (LPO) products are counteracted by the antioxidative defense system (AOS), which consists of nonenzymatic antioxidant molecules such as tocopherol, carotenoids, ascorbate, glutathione (Briviba and Sies, 1994) and the antioxidant enzymes superoxide dismutase (SOD), catalase (CAT), glutathione peroxidase (GPx), glutathione reductase (GR), and glutathione transferase (GST). SOD, the first line of defense against oxygen free radicals, catalyzes dismutation of superoxide anion radical into hydrogen peroxide $\left(\mathrm{H}_{2} \mathrm{O}_{2}\right)$, which can be transformed into water and oxygen by CAT or GPx. Besides hydrogen peroxide, GPx also reduces lipid or nonlipid hydroperoxides while oxidizing glutathione (GSH). The oxidized GSH is then reduced by GR (Yu, 1994). Antioxidants show different patterns during neoplastic

Corresponding author: Dr. Snežana B. Pajović, Principal scientist, Laboratory for Molecular Biology and Endocrinology, Vinča Institute for Nuclear Sciences, P. O. Box 522, 11001 Belgrade, Serbia, Tel +381 (11) 2455561 , Fax +381 (11) 2455 561, E-mail: pajovic@vin.bg.ac.yu 
transformation and tumor cells exhibit high variability of antioxidant enzymes (AOE) activities, when compared to their appropriate normal cell counterparts (Sun, 1990).

Endometrial carcinoma is the most frequently diagnosed malignancy of the female genital tract. It is often preceded by histopathologic lesions known as endometrial hyperplasia (Mutter, 2002), which denotes a set of mixed epithelial and stromal proliferations (Longacre et al., 1995), and is generally considered as precursor of endometrial cancer. Recently, a new concept of classification (EIN nomenclature) has been proposed by Mutter et al. (2000), based on integrated morphological, genetic, molecular, cell biological, and morphometrical studies, according to which three disease categories are discerned, namely, benign hyperplasia, endometrial intraepithelial neoplasia (EIN) and cancer (Baak and Mutter, 2005).

Although endometrial hyperplasia is regarded as a preliminary stage of endometrioid carcinomas (Hammond and Johnson, 2004), there is a lack of data on the relationship between oxidative stress and antioxidant enzymes in such patients. Some investigations so far have revealed elevated levels of lipid peroxidation and perturbed AOE activities in peripheral circulation and tissues of women with benign and malign diagnosis. Chiou and $\mathrm{Hu}$ (1999) reported lowered plasma and erythrocytes SOD activity of both uterine cervicitis and myoma patients, while the activities of CAT and GPx were elevated in cervicitis patients and lowered in myoma patients. Similar observations on erythrocytes SOD, CAT and GPx activities of cervicitis patients were made by Manoharan et al. (2004), whereas activities of examined enzymes decreased in cervical cancer patients. Previous results of Kolanjiappan et al. (2002) and Manoharan et al. (2002) also demonstrated an elevated level of lipid peroxidation, lowered concentrations of GSH, vitamin $\mathrm{E}$ and CAT, disturbed antioxidant status as well as altered $\mathrm{Na}+\mathrm{K}+-\mathrm{ATPase}$ activity in erythrocytes of cervical cancer patients.
In the current study we explored the level of lipid peroxidation in plasma and AOE activities in blood cells of patients diagnosed with uterine myoma (a hard benign growth that forms on the muscle layer), endometrial polypus (localized overgrowths of the endometrium that project into the uterine cavity), hyperplasia simplex, hyperplasia complex and adenocarcinoma in order to evaluate the extent of oxidative stress in blood of such patients.

\section{METHODS}

\section{Subjects}

The material used in this study consisted of 103 blood specimens of women admitted to the Department of Gynecology and Obstetrics from November 2001 to March 2003 for gynecological evaluation within routine checkups or for abnormal uterine bleeding. The specimens were taken after obtaining informed consent and the study was conducted prospectively. The protocol was consistent with the World Medical Association Declaration of Helsinki (Ethical Principles for Medical Research Involving Human Subjects).

On the basis of diagnosis and histological examination, subjects were divided into following groups: healthy control patients $(C, n=15$, mean \pm SEM: $49 \pm 3 \mathrm{yr}$ ); patients with benign uterine changes: polypus endometrii (PE, $\mathrm{n}=18$, $45 \pm 3 \mathrm{yr}$ ) or uterus myomatosus (UM, $\mathrm{n}=12$, $47 \pm 2 \mathrm{yr}$ ); patients with abnormal bleeding: hyperplasia simplex endometrii $(\mathrm{SH}, \mathrm{n}=31$, $48 \pm 1 \mathrm{yr}$ ), hyperplasia complex endometrii $(\mathrm{CH}, \mathrm{n}=22,48 \pm 2 \mathrm{yr})$ or adenocarcinoma endometrii, stage I (ACE, $\mathrm{n}=5,59 \pm 3 \mathrm{yr}$ ).

\section{Samples}

Venous blood samples were collected into heparinized tubes on the same day of endometrial biopsy and aliquoted immediately. For SOD assay (OxisResearch $\left.^{\mathrm{TM}}\right)$, blood was centrifuged at $2500 \mathrm{~g}$ for $5 \mathrm{~min}$. Plasma was discarded and pellet was resuspended in 4 packed-cell 
volume of ice-cold demineralized ultrapure water (MilliQ reagent grade water system, Millipore Corp., Bedford, MA, USA). After addition of ethanol/chloroform extraction reagent $(62.5 / 37.5 \mathrm{vol} / \mathrm{vol})$ to remove hemoglobin interference, samples were centrifuged at $3000 \mathrm{~g}$ for $10 \mathrm{~min}$ (Eppendorf centrifuge 5417, Eppendorf AG, Hamburg, Germany). Upper aqueous layer was collected and kept at $-70^{\circ} \mathrm{C}$ until assay. For GPx, GR and LPO assay $\left(\right.$ OxisResearch $\left.{ }^{\mathrm{TM}}\right)$, blood was centrifuged at $1000 \mathrm{~g}$ for $15 \mathrm{~min}$ to separate the plasma and blood cells. Plasma was stored at $-70^{\circ} \mathrm{C}$ until LPO assay, while blood cells were subjected to further sample preparation according to the assay procedure. For GPx assay, cells were washed once with 10 volumes of cold saline and then lysed by 4 volumes of ice-cold water, and activity was measured in crude lysates. For GR assay, they were washed twice in cold saline and lysed in 4 packed-cell volumes of cold water. Lysate was then centrifuged at 8500 $\mathrm{g}$ for 10 minutes to remove the red cell stroma. For CAT assay, blood cells from the pellet were washed twice in cold saline and lysed in twenty volumes of cold water.

Blood cells lysates were kept at $-70^{\circ} \mathrm{C}$ until assay. All assays were performed spectrophotometrically (Perkin Elmer Spectrophotometer, Lambda 25, Perkin Elmer Instruments, Norwalk, CT, USA).

The specific enzyme activities were expressed as Units (U) or mU per milligram of total cell protein ( $\mathrm{U}$ or $\mathrm{mU} / \mathrm{mg}$ protein). Lipid hydroperoxide $(\mathrm{LOOH})$ concentration was expressed as $\mathrm{nmol} / \mathrm{mg}$ protein. Determination of protein concentration was performed in crude hemolysates by the method of Lowry et al. (1951) and expressed as $\mathrm{mg} / \mathrm{ml}$.

\section{Assays}

Assay of SOD activity. Determination of SOD activity was performed using Oxis Bioxytech ${ }^{\circledR}$ SOD-525 $5^{\mathrm{TM}}$ Assay (Oxis International, Inc., Portland, OR, USA). The method is based on SOD-mediated increase of autoxidation of $5,6,6 \mathrm{a} 11 \mathrm{~b}$ $\mathrm{t}$ e $\mathrm{t} \mathrm{r}$ a h y d r o $-3,9,10$ tryhydroxybenzo[c]fluorene in aqueous alkaline solution to yield a chromophore with maximum absorbance at $525 \mathrm{~nm}$. The SOD activity is determined from the ratio of the autoxidation rates in the presence (Vs) and in the absence (Vc) of SOD. One SOD-525 activity unit is defined as the activity that doubles the autoxidation rate of the control blank.

Assay of CAT activity. CAT activity was determined by the method of Beutler (1982). The reaction is based on the rate of $\mathrm{H}_{2} \mathrm{O}_{2}$ degradation by catalase contained in the examined samples. The reaction was performed in an incubation mixture containing $1 \mathrm{M}$ Tris- $\mathrm{HCl}, 5 \mathrm{mM}$ EDTA, $\mathrm{pH}$ 8.0, and monitored spectrophotometrically at $230 \mathrm{~nm}$. One unit of CAT activity is defined as $1 \mu \mathrm{mol}$ of $\mathrm{H}_{2} \mathrm{O}_{2}$ decomposed per minute under the assay conditions.

Assay of GPX activity. GPx activity was assessed using the Oxis Bioxytech $®$ GPx$340^{\mathrm{TM}}$ Assay (Oxis International, Inc., Portland, OR, USA), based on the principle that oxidized glutathione (GSSG) produced upon reduction of an organic peroxide by GPx, is immediately recycled to its reduced form (GSH) with concomitant oxidation of NADPH to NADP+. The oxidation of NADPH was monitored spectrophotometrically as a decrease in absorbance at $340 \mathrm{~nm}$. One GPx-340 unit is defined as $1 \mu \mathrm{mol}$ of NADH oxidized per minute under the assay conditions.

Assay of GR activity. Activity of GR was measured using the Oxis Bioxytech $\AA$ GR$340^{\mathrm{TM}}$ Assay (Oxis International, Inc., Portland, OR, USA). Assay is based on the oxidation of NADPH to NADP+ during the reduction of oxidized glutathione (GSSG), catalyzed by a limiting concentration of glutathione reductase. The oxidation of NADPH was monitored spectrophotometrically as a decrease in absorbance at $340 \mathrm{~nm}$. One GR-340 unit is defined as $1 \mu \mathrm{mol}$ of NADH oxidized per minute under the assay conditions.

Lipid hydroperoxides. Concentration of $\mathrm{LOOH}$ in plasma was measured by Oxis Bioxytech ${ }^{\circledR}$ LPO-560 ${ }^{\mathrm{TM}}$ Assay (Oxis International, Inc., Portland, OR, USA), which is based on the oxidation of ferrous $(\mathrm{Fe} 2+)$ ions to ferric $(\mathrm{Fe} 3+)$ ions by hydroperoxides under acidic conditions. 
Ferric ions then bind with the indicator dye, xylenol orange, and form a colored complex. The absorbance of the complex was measured at $560 \mathrm{~nm}$. Since hydrogen peroxide content in many biological samples is much higher than that of other hydroperoxides, samples were pretreated with catalase to decompose the existing $\mathrm{H} 2 \mathrm{O} 2$ and eliminate the interference.

\section{Statistical analysis}

Statistical analysis was carried out by Kruskal-Wallis method and significances were evaluated by Mann-Whitney test (values marked with asterisk(s) are significantly different from control, $* \mathrm{p}<0.05, * * \mathrm{p}<0.01, * * * \mathrm{p}<0.001)$ and Dunn's test (values which are not sharing the same letter are significantly different, $\mathrm{p}<0.05)$. Spearman's rank correlation coefficient was used to investigate associations between lipid peroxidation and antioxidant enzyme activities. Two-tailed $p$ values are given throughout.

\section{RESULTS}

Comparing data for the level of lipid hydroperoxides and antioxidant enzyme activities among six diagnosis groups, all parameters showed significant variations of the obtained values (Kruskal-Wallis, LOOH: $\mathrm{H}=28.38, \mathrm{df}=5, \mathrm{p}<0.001 ;$ SOD: $\mathrm{H}=46.83, \mathrm{df}=5, \mathrm{p}<0.001 ; \mathrm{CAT}: \mathrm{H}=16.58$, $\mathrm{df}=5, \mathrm{p}<0.01 ; \mathrm{GPx}: \mathrm{H}=48.77, \mathrm{df}=5$, $\mathrm{p}<0.001$, GR: $\mathrm{H}=37.92, \mathrm{df}=5, \mathrm{p}<0.001 ; \mathrm{H}$ value indicates the discrepancies among the rank sums).

Figure 1 indicates the plasma levels of lipid peroxidation in the examined groups of patients. Compared to controls, lipid hydroperoxides concentration was comparable to that observed in patients diagnosed with polypus endometrii, whereas it was significantly higher in uterine myoma $(27 \%, \mathrm{p}<0.05)$, in both types of hyperplasia $(\mathrm{SH}, 41 \% ; \mathrm{CH}, 52 \%$; $\mathrm{p}<0.001)$ and adenocarcinoma $(57 \%$, $\mathrm{p}<0.01)$. Also, patients with simple hyperplasia had higher levels of $\mathrm{LOOH}$ than patients with polypus $(\mathrm{p}<0.05)$.
Superoxide dismutase activity (Fig 2) in myoma patients was similar to controls, and it was significantly decreased in patients with polypus $(25 \%, \mathrm{p}<0.05)$, hyperplasia simplex $(42 \%, \mathrm{p}<0.001)$, hyperplasia complex $(45 \%, \mathrm{p}<0.001)$, and adenocarcinoma $\quad(53 \%, \quad \mathrm{p}<0.01)$. Significant differences $(\mathrm{p}<0.05)$ between patients with hyperplasia or adenocarcinoma and the patients with myoma were also observed.

Catalase activity is shown in Figure 3. Compared with controls, it was not altered in blood of subjects with polypus, myoma, hyperplasia simplex and adenocarcinoma (3\%, 9\%, 12\% and 10\%, respectively, $\mathrm{p}>0.05)$, and significantly elevated $(24 \%$, $\mathrm{p}<0.01)$ in subjects with hyperplasia complex. Among groups, CAT activity differed between patients diagnosed with hyperplasia complex and polypus endometrii $(\mathrm{p}<0.05)$.

Figure 4 shows glutathione peroxidase activity. Patients with endometrial polyp had 26\% increased GPx activity $(\mathrm{p}<0.05)$ over controls, while in other patient groups the activity was not changed in uterine myoma and lowered by $27 \%$ and $35 \%$ $(\mathrm{p}<0.001)$ in hyperplasia simplex and complex, respectively, and $37 \%(\mathrm{p}<0.01)$ in adenocarcinoma subjects. Also, patients with either form of hyperplasia or adenocarcinoma had significantly decreased GPx activity $(\mathrm{p}<0.05)$ compared to patients with polypus.

Glutathione reductase activity is shown in Figure 5. Compared to control values, significant reduction of GR activity was recorded in all examined groups, namely, polypus endometrii $(65 \%)$, uterine myoma (44\%), hyperplasia simplex $(52 \%)$, hyperplasia complex $(51 \%)(\mathrm{p}<0.001)$, and adenocarcinoma $51 \% \quad(\mathrm{p}<0.01)$. No significant difference $(\mathrm{p}>0.05)$ was found among patients with either form of diagnosis.

Plasma level of lipid hydroperoxides was negatively correlated to SOD $(r=-0.33$, $\mathrm{p}<0.001)$ and GPx activity $(\mathrm{r}=-0.42$, $\mathrm{p}<0.001)$, and positively correlated to CAT activity $(\mathrm{r}=0.28, \mathrm{p}<0.01)$. Also, no correlation was found between lipid hydroperoxides and GR activity (Fig 6). 


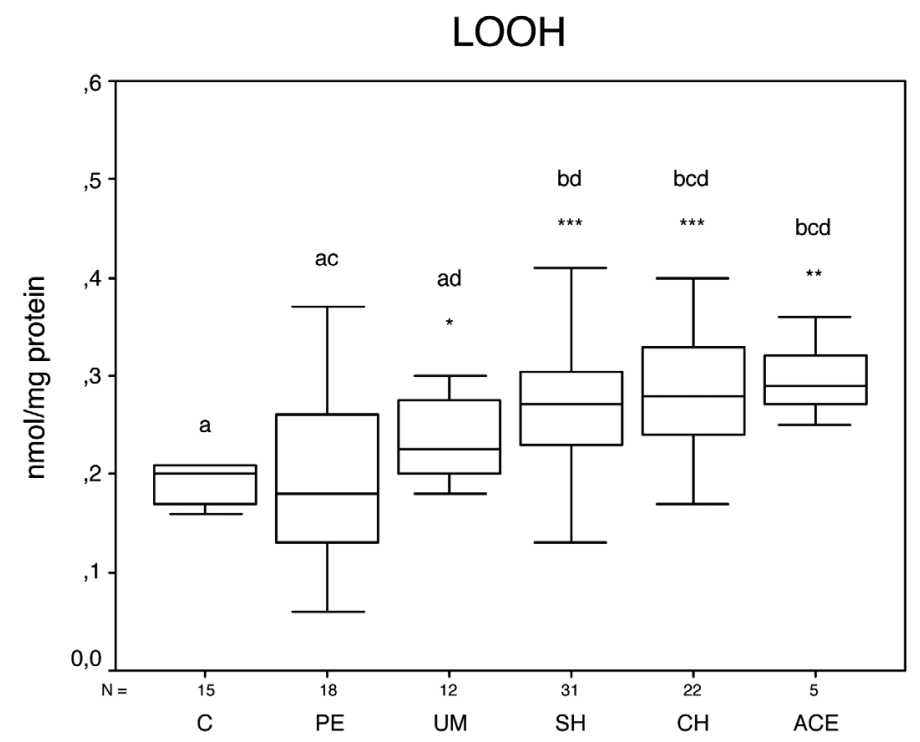

Figure 1: $\mathrm{LOOH}$ concentration in plasma of control patients $(\mathrm{C})$ and patients diagnosed with: polypus endometrii (PE), uterus myomatosus (UM), simple hyperplasia ( $\mathrm{SH})$, complex hyperplasia $(\mathrm{CH})$ and adenocarcinoma endometrii $(\mathrm{ACE})$. Mean LOOH concentrations $( \pm \mathrm{SD})$ are represented by the box; medians are plotted inside a box; the whiskers extend to the 5th and 95th percentiles. Number of patients $(\mathrm{N})$ for each group is shown below the $\mathrm{x}$ axis. Values which are not sharing the same letter $(\mathrm{a}, \mathrm{b}, \mathrm{c}, \mathrm{d})$ are significantly different $(\mathrm{p}<0.05)$. Values marked with asterisk(s) are significantly different $(* \mathrm{p}<0.05, * * \mathrm{p}<0.01, * * * \mathrm{p}<0.001)$ from control.

\section{SOD}

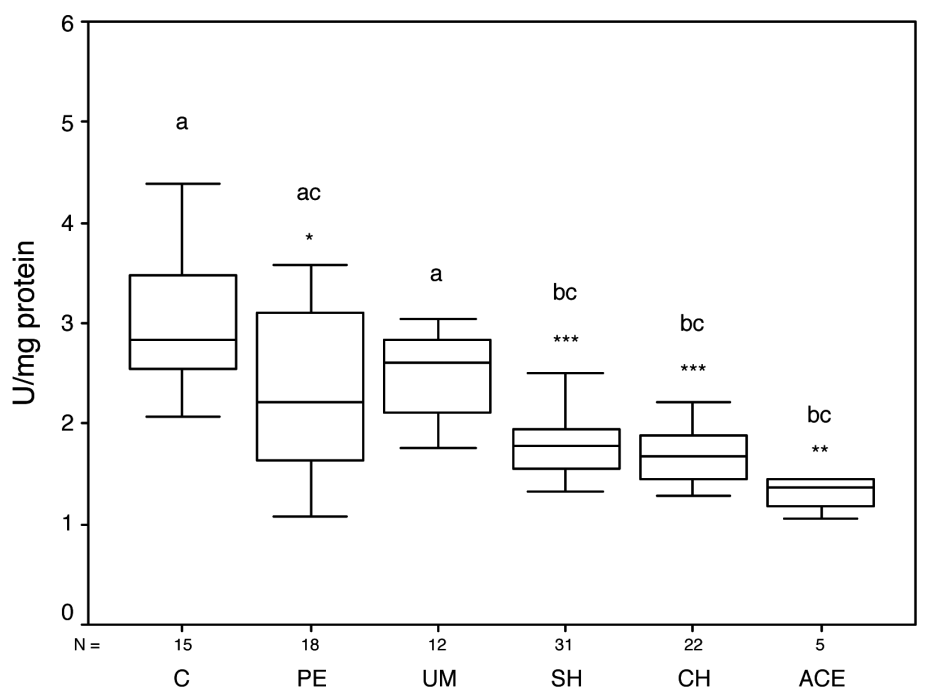

Figure 2: SOD activity in blood of control patients (C) and patients diagnosed with: polypus endometrii (PE), uterus myomatosus (UM), simple hyperplasia $(\mathrm{SH})$, complex hyperplasia $(\mathrm{CH})$ and adenocarcinoma endometrii (ACE). Mean SOD activities $( \pm \mathrm{SD})$ are represented by the box; medians are plotted inside a box; the whiskers extend to the 5th and 95th percentiles. Number of patients $(\mathrm{N})$ for each group is shown below the $\mathrm{x}$ axis. Values which are not sharing the same letter $(\mathrm{a}, \mathrm{b}, \mathrm{c})$ are significantly different $(\mathrm{p}<0.05)$. Values marked with asterisk $(\mathrm{s})$ are significantly different $(* \mathrm{p}<0.05, * * \mathrm{p}<0.01, * * * \mathrm{p}<0.001)$ from control. 


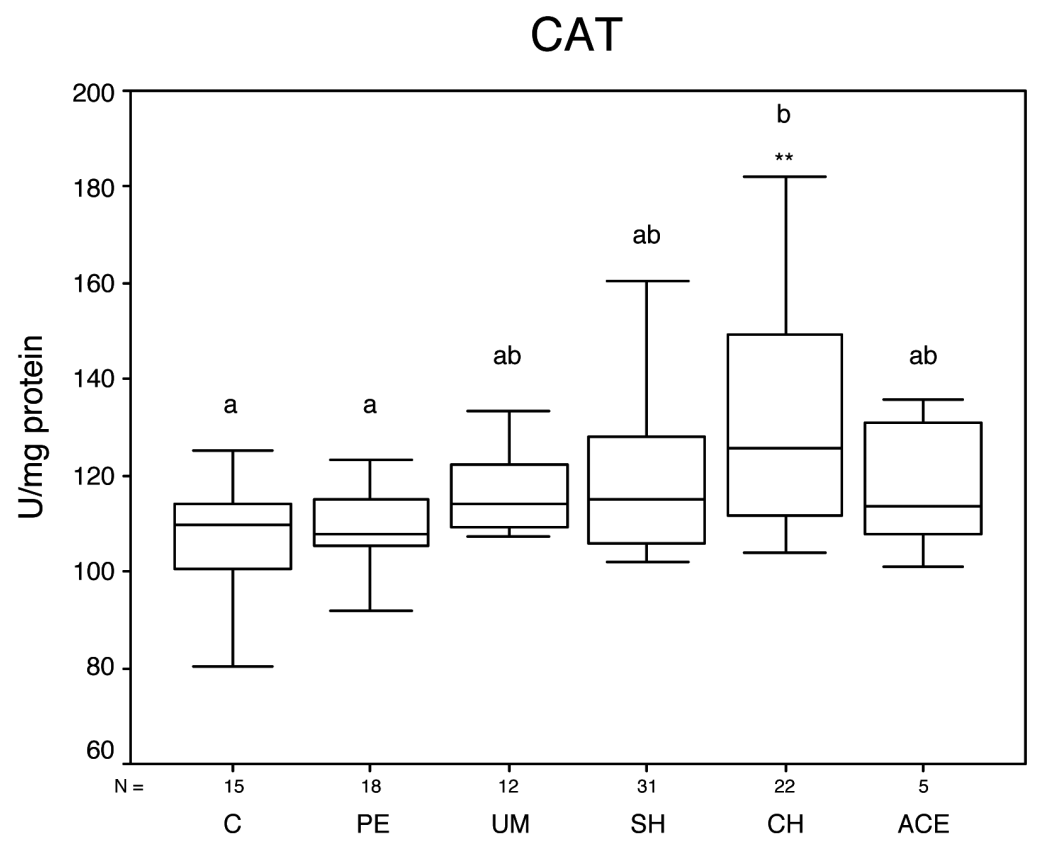

Figure 3: CAT activity in blood of control patients (C) and patients diagnosed with: polypus endometrii (PE), uterus myomatosus (UM), simple hyperplasia $(\mathrm{SH})$, complex hyperplasia $(\mathrm{CH})$ and adenocarcinoma endometrii (ACE). Mean CAT activities $( \pm \mathrm{SD})$ are represented by the box; medians are plotted inside a box; the whiskers extend to the 5th and 95th percentiles. Number of patients $(\mathrm{N})$ for each group is shown below the $\mathrm{x}$ axis. Values which are not sharing the same letter $(\mathrm{a}, \mathrm{b})$ are significantly different $(\mathrm{p}<0.05)$. Value marked with asterisks is significantly different $(* * \mathrm{p}<0.01)$ from control.

The $\mathrm{LOOH} / \mathrm{GPx}$ ratio was also calculated, and for each group the value was $0.011(\mathrm{C}), 0.009(\mathrm{PE}), 0.017$ (UM), $0.023(\mathrm{SH}), 0.026(\mathrm{CH})$, and $0.028(\mathrm{ACE})$. Except polypus patients, it was significantly higher in all examined groups (UM, $\mathrm{p}<0.05$; $\mathrm{SH}, \mathrm{CH}, \mathrm{ACE}, \mathrm{p}<0.001)$, relative to control values. The comparison among groups revealed significant elevation $(\mathrm{p}<0.05)$ of the $\mathrm{LOOH} / \mathrm{GPx}$ ratio in $\mathrm{UM}, \mathrm{SH}, \mathrm{CH}$ and ACE patients vs PE subjects, and also a significant ratio increment in $\mathrm{CH}$ and $\mathrm{ACE}$ patients vs UM subjects $(\mathrm{p}<0.05)$.

\section{DISCUSSION}

Evidence indicates that free radical species and their derivatives are the key denominators in a number of pathological conditions, including carcinogenesis (Maeda and Akaike, 1998). Although it is not clear whether oxidative stress and tumor result from an increased oxidant production or from a failure of antioxidant defense system (Toyokuni et al., 1995), impairment of the AOS is considered to be critically involved in such conditions. In neoplastic transformation, antioxidant enzyme activities have shown different patterns and they are highly variable in tissues and blood of patients with different types of cancer (Ahmed et al., 1999; Hristozov et al., 2001; Abiaka et al., 2002).

This study indicates that antioxidant defense mechanisms are impaired in human uterine diseases and it also points to elevated levels of lipid peroxidation products, as markers of oxidative stress, in plasma of such patients. Namely, higher levels of $\mathrm{LOOH}$ as well as the LOOH/GPx ratio were recorded in all examined groups over those in controls, except for patients with polypus endometrii. The observed changes are in accordance with other findings where elevated lipid peroxidation 


\section{GPx}

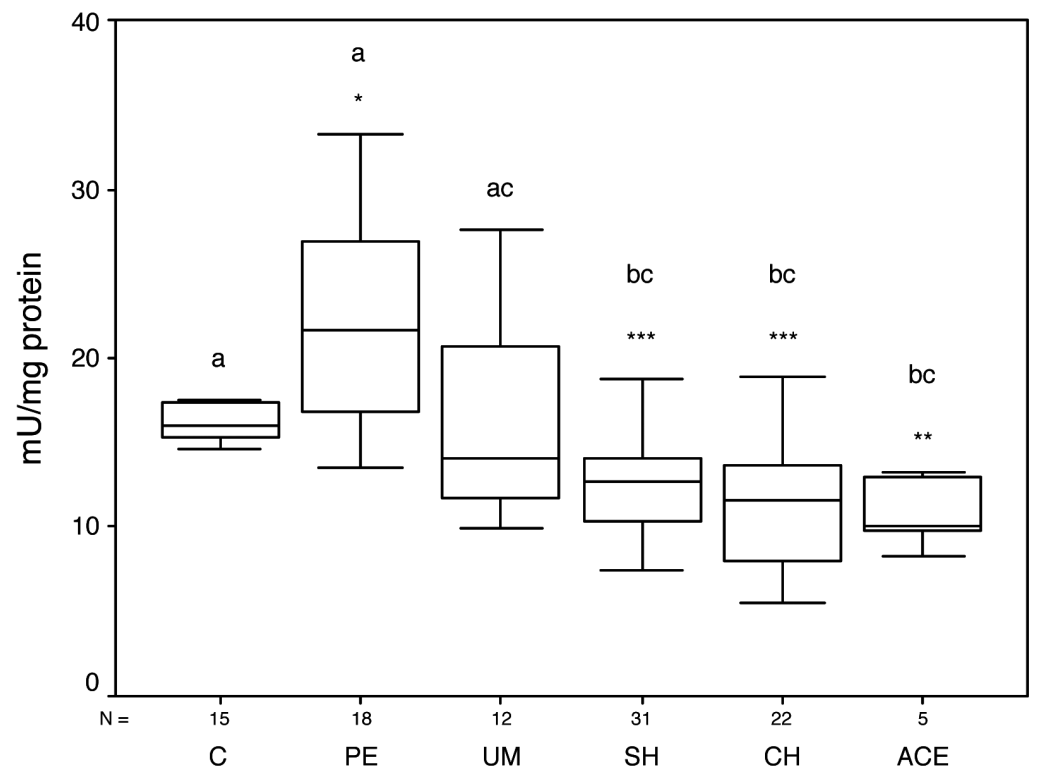

Figure 4: GPx activity in blood of control patients (C) and patients diagnosed with: polypus endometrii (PE), uterus myomatosus (UM), simple hyperplasia $(\mathrm{SH})$, complex hyperplasia $(\mathrm{CH})$ and adenocarcinoma endometrii (ACE). Mean GPx activities $( \pm \mathrm{SD})$ are represented by the box; medians are plotted inside a box; the whiskers extend to the 5th and 95th percentiles. Number of patients $(\mathrm{N})$ for each group is shown below the $\mathrm{x}$ axis. Values which are not sharing the same letter $(\mathrm{a}, \mathrm{b}, \mathrm{c})$ are significantly different $(\mathrm{p}<0.05)$. Values marked with asterisk $(\mathrm{s})$ are significantly different $(* \mathrm{p}<0.05, * * \mathrm{p}<0.01, * * * \mathrm{p}<0.001)$ from control.

was reported for patients with uterine cervicitis or myoma (Chiou and $\mathrm{Hu}, 1999$ ) or cancer patients (Manju et al., 2002; Kolanjiappan et al., 2002). We also observed that circulating levels of lipid hydroperoxides and LOOH/GPx ratio are generally higher in subjects with either form of hyperplasia or adenocarcinoma than those found in polypus or myoma patients. Oxygen radical production, which elevates lipid peroxidation, increases with clinical progression of diseases (Bagchi and Puri, 1998; Skrzydlewska et al., 2005). Since patients with either form of hyperplasia or adenocarcinoma have 2.53.11-fold and 1.35-1.65-fold increase in the LOOH/GPx ratio compared to polypus or myoma subjects, respectively, this might indicate that such patients potentially have wider extent of cellular membrane alterations (van Ginkel and Sevanian, 1994) or DNA damage (Toyokuni, 1998). The increase in $\mathrm{LOOH}$ may also be due to the impaired antioxidant system as observed in the previous studies (Hristozov et al., 2001; Manoharan et al., 2004).

Superoxide dismutase, a scavenger of superoxide anions, along with catalase and glutathione peroxidase, the preventive antioxidants, play a very important role in protection against lipid peroxidation. In this study, SOD activities were lower in blood of all examined patient groups than in healthy subjects. Besides, decrease of SOD activity was much more pronounced in hyperplasia or adenocarcinoma patients than in subjects with polypus or myoma, thus making those individuals more vulnerable to oxidative stress. Decreased SOD activity in plasma of gynecological patients was also reported by Bhuvaraharamurthy et al. (1996), Chiou and $\mathrm{Hu}$ (1999), Manoharan et al. (2004). Reduction of SOD activity may be due to an increased endogenous production of ROS as evidenced by increased lipid 


\section{GR}

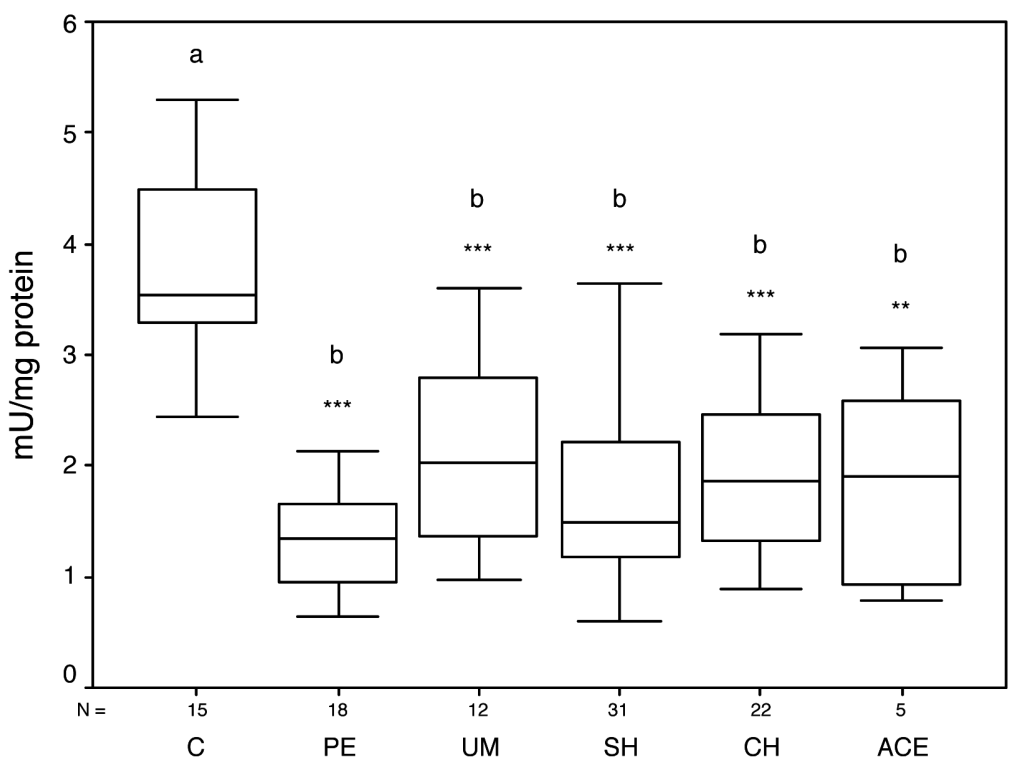

Figure 5: GR activity in blood of control patients $(\mathrm{C})$ and patients diagnosed with: polypus endometrii (PE), uterus myomatosus (UM), simple hyperplasia $(\mathrm{SH})$, complex hyperplasia $(\mathrm{CH})$ and adenocarcinoma endometrii (ACE). Mean GR activities $( \pm \mathrm{SD})$ are represented by the box; medians are plotted inside a box; the whiskers extend to the 5th and 95th percentiles. Number of patients $(\mathrm{N})$ for each group is shown below the $\mathrm{x}$ axis. Values which are not sharing the same letter $(\mathrm{a}, \mathrm{b})$ are significantly different $(\mathrm{p}<0.05)$. Values marked with asterisk(s) are significantly different $(* * \mathrm{p}<0.01, * * * \mathrm{p}<0.001)$ from control.

hydroperoxides. In support of this observation, plasma $\mathrm{LOOH}$ were found to be negatively correlated with SOD activities in the examined patients.

Compared with controls, significant elevation of CAT activity was recorded only in patients with hyperplasia complex while mild elevation was observed in the other groups. However, GPx activity was significantly increased only in patients with polypus endometrii. Other groups had lowered GPx activity, which was significant for the subjects diagnosed with either form of hyperplasia or adenocarcinoma. The observed changes also point to different antioxidant defense properties in various gynecological pathologies. Previous studies have reported elevated CAT and GPx activities in cervicitis patients (Chiou and $\mathrm{Hu}, 1999$; Manoharan et al., 2004) and lowered activities of these enzymes in myoma patients (Chiou and $\mathrm{Hu}, 1999$ ). In cancer patients, both lowered (Chiou and $\mathrm{Hu} 1999$; Manoharan et al., 2004) and increased (Mila-Kierzenkowska et al., 2004) CAT activity in blood was observed.

Catalase is considered to play a greater role in protecting erythrocytes against oxidative stress than GPx (Gaetani et al., 1996; Mueller et al., 1997) although their significance in $\mathrm{H}_{2} \mathrm{O}_{2}$ decomposition is still not clear (Nagababu et al., 2003). Also it is well known that reactive oxygen metabolites such as hydrogen peroxide and superoxide anion increase in various pathological conditions and superoxide anion radical inactivates CAT (Kono and Fridovich, 1982) and GPx (Blum and Fridovich, 1985). Decreased SOD activity, observed in this study, would be expected to further elevate superoxide anion levels. It was also proposed that superoxide anion channel allows the transport of superoxide and other free radicals into the red cell, where they are deactivated by the 

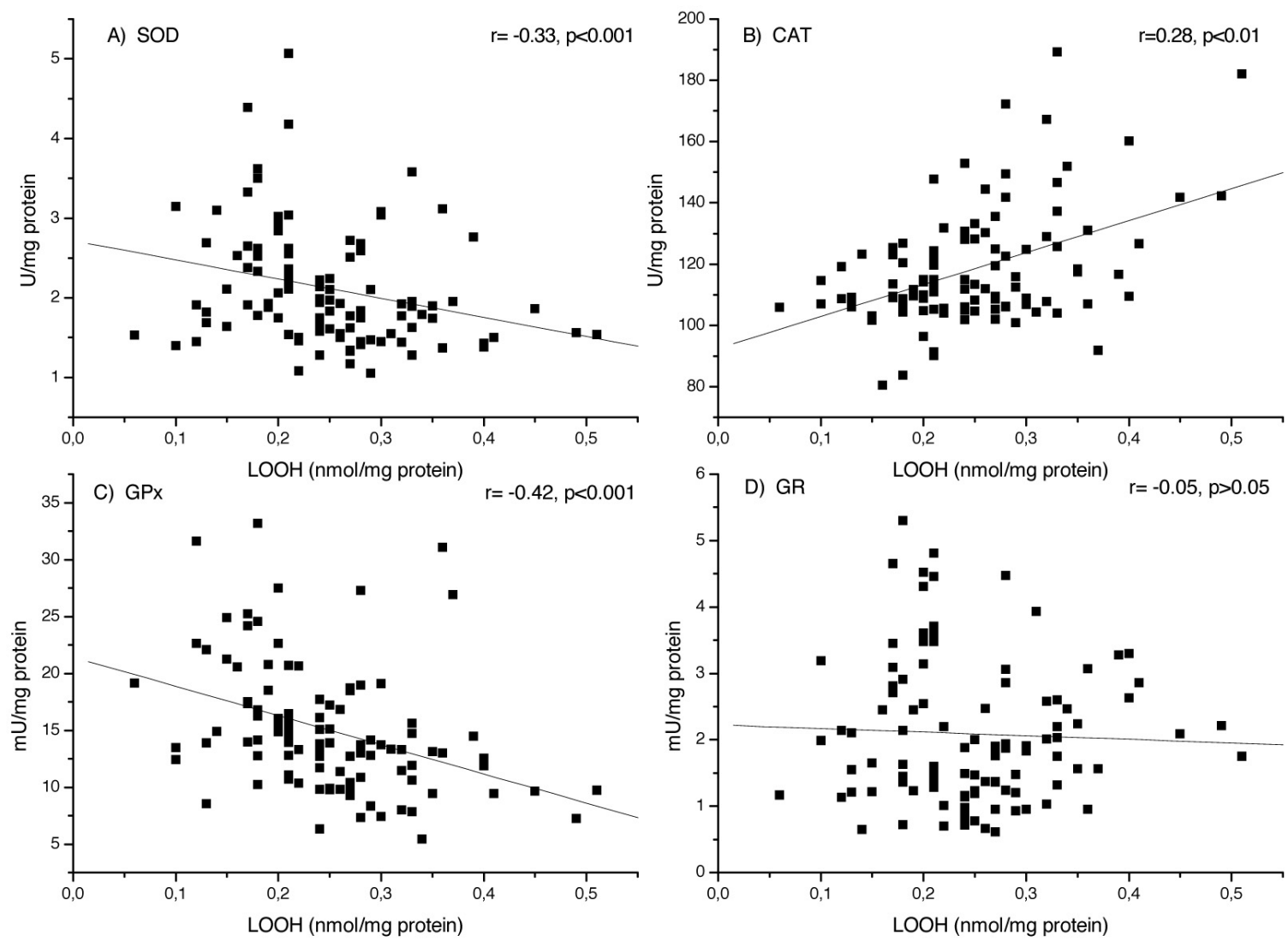

Figure 6: Scatter plot of SOD (A), CAT (B), GPx (C), and GR (D) activities against LOOH level.

erythrocyte antioxidant system (Richards et al., 1998). According to our results, in blood of examined gynecological patients, CAT activity seems to be unimpaired and GPx enzyme seems to be more sensitive to elevated levels of superoxide. In addition, lipid hydroperoxides were found to be positively correlated with CAT and negatively correlated with GPx activities in the examined patients.

Besides, decreased GPx activity, recorded in all groups except in polypus patients, might also be due to depletion of glutathione. Namely, oxidative stress was shown to induce the efflux of oxidized glutathione, consequently decreasing its content in erythrocytes and leading to their shorter life (Prchal et al., 1975; Thom et al., 1997; Sharma et al., 2000). Similar observation was made by Manoharan et al. (2004) for cervical cancer patients and it was further supported with the finding of lowered glucose 6-phosphate dehydrogenase activity and NADPH production. Remarkably reduced glutathione reductase activity recorded in our study is in accordance with these observations. Also, reduction of erythrocyte GPx and GR activities besides GSH depletion is considered responsible for increased heme degradation as shown by Nagababu et al. (2003). Similar findings on GPx and GR activities in our study could also point to further deterioration of oxidative stress conditions based on heme degradation in gynecological patients.

In summary, this study shows that patients with polypus or myoma, or either form of hyperplasia or adenocarcinoma have enhanced lipid peroxidation and $\mathrm{LOOH} / \mathrm{GPx}$ ratio, as well as altered activities of antioxidant enzymes in peripheral blood circulation. Although alterations vary with the enzyme type and diagnosis, both reduction in antioxidants and elevation of lipid peroxidation were observed in general. The lowered activity of 
antioxidant enzymes in gynecological patients could be a result of disturbed redox status, while elevated lipid peroxidation seems to be a consequence of the disease rather than its cause. Furthermore, the $\mathrm{LOOH} / \mathrm{GPx}$ ratio, which increases with the severity of the disease, suggests a greater oxidative stress status that can be related to the different uterine pathology. Such ratio could also be taken as an indicative parameter of oxidative stress in blood of gynecological patients.

It is known that in response to acute oxidative stress antioxidants may be consumed to prevent oxidative damage, and then may be supplied through the antioxidant network. However, in the cases of the observed gynecological pathologies it seems that prolonged oxidative stress elevates free radical production and induces consumption of antioxidants, which in turn further aggravate the free radical damage and increase the chance of developing uterine cancer. Indeed, the results obtained in this study show that observed changes of AO status, LOOH level, and LOOH/GPx ratio in peripheral circulation of gynecological patients are more pronounced in premalignant (hyperplastic) and malignant (ACE) lesions, compared with benign uterine changes (polypus and myoma). Further investigation should determine whether lipid hydroperoxides level and AOE activities in blood of such patients might be used as additional parameter in clinical evaluation of gynecological disorders.

\section{ACKNOWLEDGEMENT}

The work was financially supported by the Ministry of Science and Environmental Protection of the Republic of Serbia (Grant 143035).

\section{REFERENCES}

ABIAKA C, AL-AWADI F, AL-SAYER H, GULSHAN S, BEHBEHANI A, FARGHALLY M (2002) Activites of erythrocyte antioxidant enzymes in cancer patients. J Clin Lab Anal 16: 167-171

AHMED MI, FAYED ST, HOSSEIN H, TASH FM (1999)
Lipid peroxidation and antioxidant status in human cervical carcinoma. Dis Markers 15: 283-291

BAAK JPA, MUTTER GL (2005) EIN and WHO94. J Clin Pathol 58: 1-6

BAGCHI K, PURI S (1998) Free radicals and antioxidants in health and disease. East Mediterr Health J 4: 350-360

BEUTLER E. (1982) Catalase. In: BEUTLER E (ed) Red Cell Metabolism, a Manual of Biochemical Methods. 3rd ed. New York: Grune and Stratton. pp: 105-106

BHUVARAHARAMURTHY V, BALASUBRAMANIAN N, GOVINDASAMY S (1996) Effect of radiotherapy and chemoradiotherapy on circulating antioxidant system of human uterine cervical carcinoma. Mol Cell Biochem 158: 17-23

BLUM J, FRIDOVICH I (1985) Inactivation of glutathione peroxidase by superoxide dismutase radical. Arch Biochem Biophys 240: 500-508

BRIVIBA K, SIES H (1994) Nonenzymatic antioxidant defense systems. In: FREI B (ed) Natural Antioxidants in Human Health and Diseases. San Diego, CA: Academic Press. pp. 107-128

CHIOU JF, HU ML (1999) Elevated lipid peroxidation and disturbed antioxidant enzyme activities in plasma and erythrocytes of patients with uterine cervicitis and myoma. Clin Biochem 32: 189-192

GAETANI GF, FERRARIS AM, ROLFO M, MANGERINI R, ARENA S, KIRKMAN HN (1996) Predominant role of catalase in the disposal of hydrogen peroxide within human erythrocytes. Blood 87: 1595-1599

HALLIWELL B (1996) Antioxidants in human health and disease. Annu Rev Nutr 16: 33-50

HAMMOND R, JOHNSON J (2004) Endometrial hyperplasia. Curr Obstet Gynaecol 14: 99-103

HRISTOZOV D, GADJEVA V, VLAYKOVA T, DIMITROV G (2001) Evaluation of oxidative stress in patients with cancer. Arch Physiol Biochem 109: 331336

KOLANJIAPPAN K, MANOHARAN S, KAYALVIZHI M (2002) Measurement of erythrocyte lipids, lipid peroxidation, antioxidants and osmotic fragility in cervical cancer patients. Clin Chim Acta 326: 143-149

KONO Y, FRIDOVICH I (1982) Superoxide radical inhibits catalase. J Biol Chem 57: 1571-1578

LONGACRE TA, KEMPSON RL, HENDRICKSON MR (1995) Endometrial hyperplasia, metaplasia and carcinoma. In: FOX H, WELLS M (eds) Obstetrical and Gynaecological Pathology. 4th ed, vol. 1. New York: Churchhill Livingstone. pp: 421-510

LOWRY OH, ROSEBROUGH NJ, FARR AL, RANDALL RJ (1951) Protein measurement with the Folin phenol reagent. J Biol Chem 193: 265-275

MAEDA H, AKAIKE T (1998) Nitric oxide and oxygen radicals in infection, inflammation, and cancer. Biochemistry (Mosc.) 63: 854-865

MANJU V, KALAIVANI-SAILAJA J, NALINI N (2002) Circulating lipid peroxidation and antioxidant status in cervical cancer patients: a case-control study. Clin Biochem 35: 621-625

MANOHARAN S, KOLANJIAPPAN K, KAYALVIZNI M, SETHUPATHY S (2002) Lipid peroxidation and antioxidant status in cervical cancer patients. J Biochem Mol Biol Biophys 6: 225-227

MANOHARAN S, KOLANJIAPPAN K, KAYALVIZNI M (2004) Enhanced lipid peroxidation and impaired enzymic antioxidant activities in the erythrocytes of patients with cervical carcinoma. Cell Mol Biol Lett 9: 699-707

MILA-KIERZENKOWSKA C, KEDZIORAKORNATOWSKA K, WOZNIAK A, DREWA T, WOZNIAK B, DREWA S, KRZYZYNSKA- 
MALINOWSKA E, MAKAREWICZ R (2004) The effect of brachytherapy on antioxidant status and lipid peroxidation in patients with cancer of the uterine cervix. Cell Mol Biol Lett 9: 511-518

MUELLER S, RIEDEL HD, STREMMEL W (1997) Direct evidence for catalase as the predominant $\mathrm{H} 2 \mathrm{O} 2$ removing enzyme in human erythrocytes. Blood 90: 4973-4978

MUTTER GL, THE ENDOMETRIAL COLLABORATIVE GROUP (2000) Endometrial Intraepithelial Neoplasia (EIN): Will it bring order to chaos? Gynecol Oncol 76: 287-290

MUTTER GL (2002) Diagnosis of premalignant endometrial disease. J Clin Pathol 55: 326-331

NAGABABU E, CHREST FJ, RIFKIND JM (2003) Hydrogen-peroxide-induced heme degradation in red blood cells: the protective roles of catalase and glutathione peroxidase. Biochim Biophys Acta 1620: 211-217

PORTER NA, CALDWELL SE, MILLS KA (1995) Mechanisms of free radical oxidation of unsaturated lipids. Lipids 30: 277-290

PRCHAL J, SRIVASTAVA SK, BEUTLER E (1975) Active transport of GSSG from reconstituted erythrocyte ghosts. Blood 46: 111-117

RICHARDS RS, ROBERTS TK, MCGREGOR NR, DUNSTAN RH, BUTT HL (1998) The role of erythrocytes in the inactivation of free radicals. Med Hypotheses 50: 363-367
SHARMA R, AWASTHI S, ZIMNIAK P, AWASTHI YC (2000) Transport of glutathione-conjugates in human erythrocytes. Acta Biochim Pol 47: 751-762

SKRZYDLEWSKA E, SULKOWSKI S, KODA M, ZALEWSKI B, KANCZUGA-KODA L, SULKOWSKA M (2005) Lipid peroxidation and antioxidant status in colorectal cancer. World J Gastroenterol 11: 403-406

SPITELLER G (2003) Are lipid peroxidation processes induced by changes in the cell wall structure and how are these processes connected with diseases? Med Hypotheses 60: 69-83

SUN Y (1990) Free radicals, antioxidant enzymes, and carcinogenesis. Free Radical Biol Med 8: 583-599

THOM SR, KANG M, FISHER D, ISCHIROPOULOS H (1997) Release of glutathione from erythrocytes and other markers of oxidative stress in carbon monoxide poisoning. J Appl Physiol 82: 1424-1432

TOYOKUNI S, OKAMOTO J, YODOI J, HIAI, H (1995) Persistent oxidative stress in cancer. FEBS Lett. 16: 3581-3583

TOYOKUNI S (1998) Oxidative stress and cancer: The role of redox regulation. Biotherapy 11: 147-154

VAN GINKEL G, SEVANIAN A (1994) Lipid peroxidation induced membrane structural alterations. Methods Enzymol 233: 273-288

YU BP (1994) Cellular defenses against damage from reactive oxygen species. Physiol Rev 74: 139-162 
